\title{
Bertrand colludes more than Cournot
}

\author{
Sigrid Suetens $\cdot$ Jan Potters
}

Received: 27 April 2006 / Revised: 14 September 2006 /

Accepted: 18 September 2006 / Published online: 31 January 2007

(C) Economic Science Association 2007

\begin{abstract}
On the basis of evidence of past oligopoly experiments, we argue that there is often significantly more tacit collusion in Bertrand price-choice than in Cournot quantity-choice markets.
\end{abstract}

Keywords Collusion - Quantity-choice and price-choice experiments

JEL Classification L00, L13, D21

\section{Introduction}

An important issue in industrial organisation is the incidence of tacit collusion. Given that Bertrand price competition and Cournot quantity competition are the two workhorse models in IO, a natural question is whether one is more prone to tacit collusion than the other. Somewhat surprisingly perhaps, this issue has not been explicitly addressed in any experiments.

Based on a survey of experimental IO research, Holt (1995) hypothesises that in Cournot settings there is less collusion than in Bertrand settings. However, apart from Fouraker and Siegel (1963), referred to as FS in what follows, the studies on which this hypothesis is based have either Cournot or Bertrand treatments, but not both.

Recently, a series of papers have investigated the impact of information feedback on behaviour in Cournot and Bertrand settings (see Huck et al., 2000; Davis, 2002; Altavilla et al., 2006, further referred to as HNO, Davis and ALS, respectively). As a

\footnotetext{
S. Suetens $(\bowtie)$

University of Antwerp, Department of Economics,

Prinsstraat 13, B-2000 Antwerp Belgium

e-mail: sigrid.suetens@ua.ac.be

J. Potters

Tilburg University, CentER, P.O.Box 90153, 5000 LE Tilburg, The Netherlands

e-mail: j.j.m.potters@uvt.nl
} 
by-product, the underlying data allow for a direct comparison of the tendency to tacitly collude between Cournot and Bertrand environments with two and more sellers. In the present paper we review the evidence and find support for Holt's hypothesis.

\section{Overview of experimental designs}

FS, HNO, Davis and ALS examine the impact of information on behaviour in experiments in which subjects play repetitions of static Cournot and Bertrand games. The reported experiments have similar designs and contain BASIC and EXTRA treatments. ${ }^{1}$ In the BASIC treatments only aggregate information was provided on the competitors' quantities or prices and no information about their profit. In the EXTRA treatments information was provided on all individual quantities or prices as well as on profits. ${ }^{2}$

Although there are differences in experimental procedures between the four studies with respect to type of matching, information about duration and number of players, these procedures are the same across Cournot and Bertrand treatments within each study.

The following inverse demand function for firm $i$ producing substitute goods is used in all Cournot treatments:

$$
p_{i}=a-b\left(q_{i}+\theta \sum_{j \neq i} q_{j}\right)
$$

with $a, b>0$ and $0<\theta \leq 1$.

In the Bertrand treatments the form of the demand function depends on whether one assumes homogeneous goods. FS assume homogeneous goods and use the following demand function:

$$
q_{i}=\left\{\begin{array}{ccc}
\frac{A-B p_{i}}{L} & : & p_{i} \leq p_{j} \\
0 & : & p_{i}>p_{j}
\end{array}\right.
$$

where $L$ is the number of producers tied for the lowest price. Only the producer setting the lowest price will produce to meet the entire demand and in case of a tie total production is evenly split up amongst the tied producers. The other Bertrand treatments are based on a setting with differentiated goods. The demand function of firm $i$, which is a transformation of inverse demand (Eq. (1)) provided that $q_{i} \geq 0$, is

$$
q_{i}=\alpha-\beta p_{i}+\gamma \frac{\sum_{j \neq i} p_{j}}{n-1}
$$

\footnotetext{
${ }^{1}$ The Cournot and Bertrand experiments of FS are discussed in part three of their book. BASIC refers to their incomplete information treatment and EXTRA to their complete information treatment. For ALS, BASIC and EXTRA respectively refer to their ED 1 and ED 3 treatments.

${ }^{2}$ In the BASIC treatments of FS subjects were not informed about their competitors' profit function. In the EXTRA treatments of FS the competitors' profit could be calculated on the basis of profit tables, apart from the Cournot triopoly treatment, where only the sum of the competitors' profit could be calculated.
} 
with

$$
\begin{aligned}
\alpha & =\frac{a}{b[1+(n-1) \theta]} \\
\beta & =\frac{1+(n-2) \theta}{b(1-\theta)[1+(n-1) \theta]} \\
\gamma & =\frac{(n-1) \theta}{b(1-\theta)[1+(n-1) \theta]} .
\end{aligned}
$$

Under Cournot competition, $\pi_{i}=\left(p_{i}-c\right) q_{i}-C$ is maximised with respect to $q_{i}$ and under Bertrand competition, with respect to $p_{i}$. FS use $a=2.4, b=0.04, \theta=1$ and $c, C=0$ in the Cournot treatments, and $A=56, B=8, c=0, C=13$ for a producer who actually produced and $C=25$ for a producer who does not produce in the Bertrand treatments. These cost parameters were chosen in order to facilitate competition. ${ }^{3}$ HNO use $a=300, b=1, \theta=2 / 3, c=2$ and $C=0$ in all treatments. Davis uses $a=225, b=1, \theta=2 / 3$ and $C=0$ in all treatments, $c=33$ in all Bertrand treatments and the EXTRA Cournot treatment and $c=1$ in the BASIC Cournot treatment. ${ }^{4}$ ALS use $a=24$ and $c, C=0$ in all treatments, $b=1 / 2$ and $\theta=1$ in the Cournot treatment with homogeneous products (C1), and $b=2 / 3$ and $\theta=1 / 2$ in the Cournot treatment with differentiated products (C2) and the Bertrand treatment.

Table 1 summarises the theoretical benchmarks that correspond to these parameter choices and includes other features (such as number of firms, number of rounds, type of matching and minimum and maximum feasible action) in the four sets of experiments ( $C$ refers to Cournot and $B$ to Bertrand). Note that in the FS, HNO and ALS experiments, theoretical benchmarks are the same across BASIC and EXTRA.

In Table 1 the Nash equilibrium choice of the stage game is in bold. In finitely repeated games with a known end, the unique subgame perfect Nash equilibrium corresponds to repeated play of the unique Nash equilibrium of the stage game. However, from earlier studies we know that even in finitely repeated games, players manage to cooperate to some degree and behave similarly as in infinitely repeated games or as in games with an unknown end (see Selten and Stoecker, 1986; Normann and Wallace, 2004). One measure for the scope for tacit collusion in a repeated game is the ratio between the gains from cooperation and the gains from defection, $\frac{\pi_{\mathrm{JPM}}-\pi_{\text {Nash }}}{\pi_{\text {Defect }}-\pi_{\mathrm{JPM}}}$, which in the table we refer to as the Friedman index after Friedman (1971). The higher the index, the higher the possibility that tacit collusion can be sustained as an equilibrium in an infinitely repeated game context as part of a grim trigger strategy. Martin (1995), van Wegberg (1995) and Potters et al. (2004), for instance, use this index to measure the scope for tacit collusion. It is clear from Table 1 that on the basis of this index one

\footnotetext{
${ }^{3}$ In the Bertrand triopolies, payoff of producers tied at the lowest price is set equal to 0 . The payoff table FS use in the Cournot treatments is a rough approximation of the payoffs based on the parameter values. In fact, all payoffs in the table are multiples of 50. The calculations in Section 3 will be based on the exact payoff function.

${ }^{4}$ Davis expected Nash behaviour under BASIC and imitation under EXTRA. Therefore he implemented different cost parameters to ensure equivalence between Nash equilibria in Bertrand and Cournot settings in the former case and between imitation equilibria in Bertrand and Cournot settings in the latter case (see Section 3 for more on the imitation equilibrium).
} 
Table 1 Summary of features of Cournot/Bertrand experiments

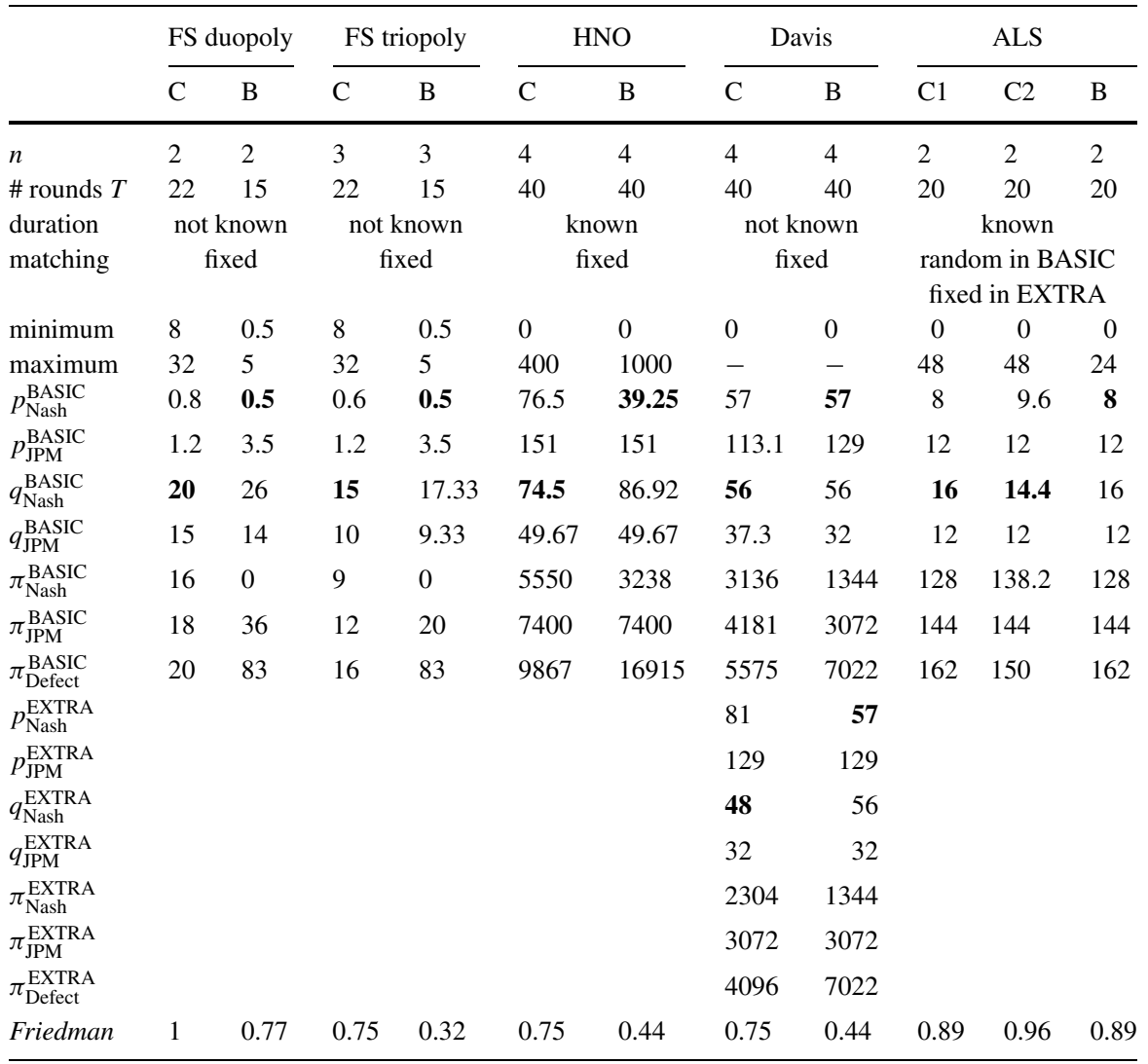

$\mathrm{JPM}=$ joint profit maximising

would a priori expect that the tendency to tacitly collude is higher in Cournot than in Bertrand treatments. For ALS one would expect the same tendency to cooperate when comparing $\mathrm{C} 1$ with $\mathrm{B}$.

\section{Degree of tacit collusion}

In this section we examine to which extent behaviour in Bertrand and Cournot treatments deviates from the Nash prediction toward full collusion. We use two alternative measures of the degree of collusion. Both are indices in which the degree of collusion of oligopoly $k$ in round $t$ is defined as follows:

$$
\rho_{k t}=\frac{\bar{x}_{k t}-x_{\mathrm{Nash}}}{x_{\mathrm{JPM}}-x_{\mathrm{Nash}}}
$$


For $\bar{x}_{k t}$ we take the average price of oligopoly $k$ in round $t$ as a first measure, and the average profit as a second measure. ${ }^{5}$ If $\rho_{k t}=0$, oligopoly $k$ behaves on average according to the Nash equilibrium of the stage game in round $t$, if $0<\rho_{k t} \leq 1$, behaviour of oligopoly $k$ in round $t$ is collusive, and if $\rho_{k t}<0$, behaviour is more competitive than in the Nash equilibrium.

Table 2 provides averages and standard deviations of the degree of collusion based on prices and profits for the different experiments, where $\bar{\rho}=\frac{1}{N T} \sum_{k=1}^{N} \sum_{t=1}^{T} \rho_{k t}$. The standard deviations refer to cross-sectional variability. ${ }^{6}$ Also included in the table for each experiment are $p$-values of Mann-Whitney- $U$ tests of $H_{0}: \bar{\rho}_{\text {Cournot }}=\bar{\rho}_{\text {Bertrand }}$ based on independent data. ${ }^{7}$

Table 2 shows that average degrees of collusion are higher in Bertrand than in Cournot treatments in all possible comparisons except under BASIC information conditions in the experiment of Davis. ${ }^{8}$ Under BASIC information conditions in the experiment of HNO, the difference is in the 'right' direction but is not significant, while the difference is highly significant under BASIC in FS and ALS. Under EXTRA information conditions, the difference between Cournot and Bertrand settings is for all experiments highly significant. In fact, in ALS, when comparing C2 and $\mathrm{B}$, the effect is so strong that it overturns the standard theoretical results that price competition leads to lower prices than quantity competition, under both BASIC and EXTRA conditions.

The finding that Bertrand environments are more prone to tacit collusion than Cournot environments is clearly in contrast to what the Friedman index predicts, thus other explanations should be looked for.

One possibility is that the location of the Nash equilibrium in the strategy spaces induces relatively competitive behaviour under Cournot and relatively cooperative behaviour in the Bertrand treatments. ${ }^{9}$ After all, in most studies both the equilibrium quantity and the equilibrium price are in the lower end of the strategy space. It should be noted though that the Bertrand games are significantly more cooperative than the

\footnotetext{
${ }^{5}$ For the Cournot treatments the price of each oligopoly member is calculated on the basis of the inverse demand function taking into account that $p_{i} \geq 0$. Another option would be to calculate the degree of collusion on the basis of the quantity decisions and benchmarks. As long as prices calculated on the basis of inverse demand curves and quantities calculated on the basis of demand curves are not below 0 , both alternatives give the same result. In the Cournot treatments of the FS experiments and in the ALS, HNO and Davis experiments zero prices and quantities had to be enforced because calculated prices and quantities were sometimes below 0 . This adjustment results in slight differences in degrees of collusion, depending on whether calculated on the basis of prices or quantities. However, all analyses based on the degree of price or quantity collusion yield exactly the same conclusions. With respect to the Bertrand treatments in the FS experiments, larger differences naturally occurred whether the degree of collusion was measured on the basis of the price choices or the calculated quantities, because the profit function defined in terms of quantities is not a linear transformation of the profit function defined in terms of prices (due to the homogeneous good environment). Yet, even with respect to FS, the conclusions of the tests are exactly the same, whether based on the degree of price or quantity collusion. For ALS BASIC we only have subject-specific decisions, such that the degree of collusion in their BASIC Cournot and Bertrand treatments is respectively calculated on the basis of quantity and price choices.

${ }^{6}$ Only pre-merger data from Davis are used for our purposes since post-merger data are ex ante asymmetric.

7 The ALS BASIC data are subject-specific (cf. random matching) and thus strictly speaking not independent. We do not have the data on profits in this treatment.

8 The same conclusions are obtained on the basis of other subsets of rounds.

${ }^{9}$ We thank one of the referees for raising this issue.
} 
Table 2 Average degrees of collusion in Cournot/Bertrand experiments and test statistics of $H_{0}$ : $\bar{\rho}_{\text {Cournot }}=\bar{\rho}_{\text {Bertrand }}$

\begin{tabular}{|c|c|c|c|c|c|c|}
\hline & \multicolumn{2}{|c|}{$\begin{array}{l}\text { BASIC } \\
\bar{\rho}\end{array}$} & \multirow[b]{2}{*}{$N$} & \multicolumn{2}{|c|}{$\begin{array}{l}\text { EXTRA } \\
\bar{\rho}\end{array}$} & \multirow[b]{2}{*}{$N$} \\
\hline & Price & Profit & & Price & Profit & \\
\hline \multicolumn{7}{|l|}{ FS duopoly } \\
\hline Cournot & $-0.12(0.16)$ & $-0.53(0.36)$ & 16 & $-0.24(0.70)$ & $-1.37(1.70)$ & 11 \\
\hline Bertrand & $0.24(0.15)$ & $0.14(0.20)$ & 17 & $0.52(0.26)$ & $0.44(0.34)$ & 10 \\
\hline$p$-value & 0.000 & 0.000 & 33 & 0.002 & 0.005 & 21 \\
\hline \multicolumn{7}{|l|}{ FS triopoly } \\
\hline Cournot & $-0.24(0.18)$ & $-0.70(0.49)$ & 16 & $-0.25(0.19)$ & $-0.78(0.49)$ & 11 \\
\hline Bertrand & $0.09(0.07)$ & $-0.25(0.26)$ & 17 & $0.18(0.06)$ & $-0.31(0.26)$ & 10 \\
\hline$p$-value & 0.000 & 0.010 & 33 & 0.000 & 0.004 & 21 \\
\hline \multicolumn{7}{|l|}{ HNO } \\
\hline Cournot & $0.01(0.03)$ & $-0.05(0.15)$ & 6 & $-0.23(0.15)$ & $-0.63(0.38)$ & 6 \\
\hline Bertrand & $0.04(0.07)$ & $0.05(0.12)$ & 6 & $0.04(0.06)$ & $-0.01(0.07)$ & 6 \\
\hline$p$-value & 0.394 & 0.394 & 12 & 0.004 & 0.002 & 12 \\
\hline \multicolumn{7}{|l|}{ Davis } \\
\hline Cournot & $0.14(0.54)$ & $-0.38(1.01)$ & 5 & $-0.50(0.09)$ & $-1.48(0.33)$ & 5 \\
\hline Bertrand & $-0.10(0.02)$ & $-0.24(0.06)$ & 5 & $-0.05(0.03)$ & $-0.12(0.07)$ & 5 \\
\hline$p$-value & 0.151 & 0.151 & 10 & 0.008 & 0.008 & 10 \\
\hline \multicolumn{7}{|l|}{ ALS } \\
\hline Cournot1 & $-0.70(0.82)$ & & 18 & $-0.86(0.69)$ & $-3.38(2.57)$ & 10 \\
\hline Cournot 2 & $-1.30(0.47)$ & & 18 & $-1.88(0.31)$ & $-8.60(1.96)$ & 10 \\
\hline Bertrand & $0.75(0.43)$ & & 18 & $0.08(0.36)$ & $-0.83(0.89)$ & 10 \\
\hline$p$-value 1 & 0.000 & & 36 & 0.006 & 0.011 & 20 \\
\hline$p$-value 2 & 0.000 & & 36 & 0.000 & 0.000 & 20 \\
\hline
\end{tabular}

Standard deviations are in brackets and $p$-values refer to a Mann-Whitney- $U$ test.

$N=$ number of independent observations for FS, HNO, Davis and ALS EXTRA and number of players for ALS BASIC.

Cournot games not in the earlier rounds, but especially in the later rounds when subjects have had ample oppontunity to learn. Nevertheless, this surely is an issue that warrants further attention from experimentalists. ${ }^{10}$

Another explanation is that under EXTRA information conditions, where detailed information is provided on the success of competitors, imitation of the most successful competitor may drive the difference between Cournot and Bertrand settings. Indeed, if players imitate the best performer of the previous round and if with a small probability players choose a random action, it can be shown that the outcome-sometimes referred to as the imitation equilibrium-is more competitive and results in a lower degree of cooperation under Cournot than under Bertrand competition. This may especially have played a role in the EXTRA treatments of the HNO and Davis experiments, where groups consisted of four players and subjects only had a profit calculator and no profit tables (see also Selten and Ostmann, 2001). However, the imitation argument is less

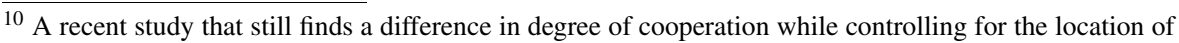
the Nash equilibrium is Potters and Suetens (2006). 
compelling under BASIC information conditions because subjects are then unable to identify the most successful competitor.

An alternative explanation is provided by the indirect evolutionary model of Bester and Güth (1998) who find that the scope for altruistic (cooperative) preferences is larger in games of strategic complements (cf. Bertrand games) than in games of strategic substitutes (cf. Cournot games). In other words, the type of strategic interdependence (strategic substitutes versus complements) may be an important determinant of the degree of tacit collusion (see also Rotemberg, 1994).

\section{Conclusion}

On the basis of experimental data from oligopoly experiments with Cournot and Bertrand treatments, we find statistical support for the suggestion of Holt (1995) that there seems to be more tacit collusion in Bertrand price-choice than in Cournot quantity-choice experiments.

Acknowledgments We gratefully acknowledge Luigi Luini, Hans Normann, Jörg Oechssler and Patrizia Sbriglia for providing their data, and Jan Bouckaert, Doug Davis, the editor (Tim Cason) and two referees of this journal for useful suggestions.

\section{References}

Altavilla, C., Luini, L., \& Sbriglia, P. (2006). Social learning in market games. Journal of Economic Behavior and Organization, forthcoming

Bester, H. \& Güth, W. (1998). Is altruism evolutionary stable? Journal of Economic Behavior and Organization, 34, 193-2092

Davis, D. D. (2002). Strategic interactions, market information and predicting the effects of mergers in differentiated product markets. International Journal of Industrial Organization, 20, 1277-1312

Fouraker, L. E., \& Siegel, S. (1963). Bargaining behavior. London: McGraw-Hill

Friedman, J. W. (1971). A non-cooperative equilibrium for supergames. Review of Economic Studies, 38, $1-12$

Holt, C. A. (1995). Industrial organization: a survey of laboratory research. In J. H. Kagel, \& A. E. Roth (Eds.), The handbook of experimental economics (pp. 349-444) New Jersey: Princeton University Press

Huck, S., Normann, H., \& Oechssler, J. (2000). Does information about competitors' actions increase or decrease competition in experimental oligopoly markets? International Journal of Industrial Organization, 18, 39-57

Martin, S. (1995). R\&D joint ventures and tacit product market collusion. European Journal of Political Economy, 11, 733-741

Normann, H. and Wallace, B. (2004). The impact of the termination rule in cooperation experiments. Department of Economics, Discussion Paper Series 2004-11, Royal Holloway College, University of London

Potters, J., Rockenbach, B., Sadrieh, A., \& van Damme, E. (2004). Collusion under yardstick competition: an experimental study. International Journal of Industrial Organization, 22, 1017-1038

Potters, J. and Suetens, S. (2006). Cooperation in experimental games of strategic complements and substitutes. CentER Discussion Paper 2006-48, University of Tilburg

Rotemberg, J. J. (1994). Human relations in the workplace. Journal of Political Economy, 102, 684-717

Selten, R., \& Ostmann, A. (2001). Imitation equilibrium. Homo Oeconomicus, 19, 119-149

Selten, R., \& Stoecker, R. (1986). End behaviour in sequences of finite prisoner's dilemma supergames. Journal of Economic Behavior and Organisation, 3, 47-70

van Wegberg M. (1995). Can R\&D alliances facilitate the formation of a cartel? The example of the European IT industry. Research Memorandum 004, Maastricht University, METEOR 